\title{
Article
}

\section{On the very idea of a recovery model for mental health}

Thornton, Tim and Lucas, Peter

Available at https://clok.uclan.ac.uk/4350/

Thornton, Tim orcid iconORCID: 0000-0002-0137-1554 and Lucas, Peter orcid iconORCID: 0000-0002-5391-3087 (2011) On the very idea of a recovery model for mental health. Journal of Medical Ethics, 37 (1). pp. 24-28. ISSN 0306-6800

It is advisable to refer to the publisher's version if you intend to cite from the work. http://dx.doi.org/10.1136/jme.2010.037234

For more information about UCLan's research in this area go to

http://www.uclan.ac.uk/researchgroups/ and search for < name of research Group>.

For information about Research generally at UCLan please go to http://www.uclan.ac.uk/research/

All outputs in CLoK are protected by Intellectual Property Rights law, including Copyright law. Copyright, IPR and Moral Rights for the works on this site are retained by the individual authors and/or other copyright owners. Terms and conditions for use of this material are defined in the policies page.

\section{CLoK}

Central Lancashire online Knowledge www.clok.uclan.ac.uk

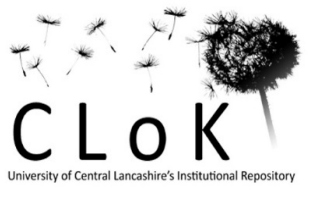


Full Title: On the very idea of a recovery model for mental health

Short title: On the very idea of a recovery model

Authors (i.e. name as it should appear on the paper):

Tim Thornton

Peter Lucas

Position (i.e. job description as it should appear on the paper):

Professor of Philosophy and Mental Health and Director of Philosophy

Senior Lecturer in Philosophy

\section{Address for correspondence:}

International School of Communities, Rights and Inclusion

University of Central Lancashire

Preston

PR1 2HE

\section{Other Contact Details:}

phone 01772895412

01772892548

fax 01772892964

email:

TThornton1@uclan.ac.uk

Plucas1@uclan.ac.uk

Key-words (not appearing in title):

eudaimonic, hedonic, normativity, function, illness

Word count (excluding title page but including references):

$\sim 4,200$

Character count (abstract):

$\sim$

Software used: Microsoft Word

\section{Filename(s):}

The Corresponding Author has the right to grant on behalf of all authors and does grant on behalf of all authors, an exclusive licence (or non exclusive for government employees) on a worldwide basis to the BMJ Publishing Group Ltd and its Licensees to permit this article (if accepted) to be published in JME and any other BMJPGL products to exploit all subsidiary rights, as set out in our licence (http://group.bmj.com/products/journals/instructions-for-authors/licenceforms).

Competing interests: there are none. 


\section{ON THE VERY IDEA OF A RECOVERY MODEL FOR MENTAL HEALTH}

\section{Introduction}

Both in the UK and internationally, the 'recovery model' has been promoted to guide mental healthcare in reaction against what is perceived to be an overly narrow traditional bio-medical model. It has also begun to have an influence in thinking more broadly about mental health both for individuals and for communities and in the latter case has been linked to policies to promote social inclusion. In this widening application, however, there is a risk that the model becomes too broad to count as a model and thus to compete with other models such as a biomedical model of health or illness.

In this short paper we sketch some of the competing views of illness and health in order to locate and articulate a possible recovery model for mental health. We suggest that a distinct recovery model could be based on a view that places values at the centre of an analysis of mental health. Our aim, however, is to clarify the options rather than defend the model that emerges.

We do, however, caution against one possible version of a recovery model. Thus if a recovery model were to be defended along the line we sketch we think that it would be better to construe the values involved on eudaimonic rather than hedonic lines.

\section{Background}

Although much recent thinking about the aims of mental healthcare stresses the role of recovery, there is little agreement about what, precisely, that means. Before going on to make their own suggestions, Larry Davidson and David Roe, for example, summarise the situation internationally thus: 'There is an increasing global commitment to recovery as the expectation for people with mental illness. There remains, however, little consensus on what recovery means in relation to mental illness' [1]. In the UK, a recent policy paper published by the Sainsbury Centre for Mental Health called 'Making recovery a reality' begins by summarising some key points of emphasis which, it is suggested, characterise any broadly recovery-based approach. These points include:

Recovery is about building a meaningful and satisfying life, as defined by the person themselves, whether or not there are ongoing or recurring symptoms or problems. Recovery represents a movement away from pathology, illness and symptoms to health, strengths and wellness.

Hope is central to recovery and can be enhanced by each person seeing how they can have more active control over their lives ('agency') and by seeing how others have found a way forward.

Self-management is encouraged and facilitated. The processes of self-management are similar, but what works may be very different for each individual. No 'one size fits all'.

The helping relationship between clinicians and patients moves away from being expert / patient to being 'coaches' or 'partners' on a journey of discovery. Clinicians are there to be "on tap, not on top".

People do not recover in isolation. Recovery is closely associated with social inclusion and being able to take on meaningful and satisfying social roles within local communities, rather than in segregated services.

Recovery is about discovering - or re-discovering - a sense of personal identity, separate from illness or disability. [2]

As this list suggests, recovery is not so much a precisely articulated explicit theoretical account of the nature of health or illness as a practical orientation to the kind of care that should be provided and the roles of patients or service users and clinicians or carers. Nevertheless, advocates of recovery in mental health often talk of a recovery model, with the 
implication that it stands in opposition to a bio-medical model of health or illness [3]. We will attempt to use the list above and a sketch of some of the debates about health and illness to suggest a possible recovery model. (A defence of the model would thus require a defence of choices made or positions adopted in those debates which we will not attempt here.)

To articulate a recovery model, in contrast, for example, to a bio-medical model, is not simply to say that recovery (construed in some broad way) is a desirable aim of mental health care.

One might hold a narrow bio-medical model based view of health or illness (of what health or illness is) whilst still thinking that the broader aims of mental health care can be characterised in the terms promoted by the recovery movement. But that would not be a recovery model and would not stand opposed to a bio-medical model (for example).

An important clue to the articulation of a model is the idea that recovery should be characterised through a positive goal of health and wellness rather than the avoidance of the negative aspects of pathology and illness. That positive goal is connected to the agency of the individual, to their own situation-specific self management of the process, and to their identity. To serve as the characteristics of a model, however, requires the additional idea that these play a role in a correct understanding of health or illness themselves. We will suggest that the presence of a normative dimension or of values in debates about health and illness provides a route to a recovery model.

The above list also connects recovery to social inclusion through the empirical claim that social inclusion promotes recovery. But given the links between policies promoting recovery at the individual level and policies promoting social inclusion at the level of communities this raises a further question that helps shed light on the connections between recovery and values: need recovery promote social inclusion? By stressing individual choice as the final arbiter of the values that form the goal of recovery, the model suggests a view of society as a group of individuals satisfying their private desires. That seems to threaten, rather than support, the notion of social inclusion and the idea of collective values or goods.

But further, if the satisfaction of just any desire can be part of the conception of recovery then the model may cease to have a connection to the idea of health. It would be not so much a corrective of the bio-medical model as a totally different venture.

We will attempt to sketch a conception of a recovery model which is distinct from a biomedical approach but which is still sufficiently normatively charged that there is some hope, at least, that it can avoid both of these risks. We will not, however, attempt to defend it against rival approaches to recovery. Our aim is to locate and characterise rather than justify a model of recovery.

\section{The normativity of illness / disease / disorder}

In the next section, we will argue that a recovery model for mental health care can be based on a view that mental health can only be characterised in evaluative terms. But to help to characterise that view it will be helpful to begin by setting out a more familiar contrast: that between an evaluative or normative versus a plainly factual view of mental illness. And to do that, we will offer a short historical context.

In his attack on the very idea of mental illness, Thomas Szasz stressed that the concept of illness, whether physical or mental, carries with it the connotation of deviation from a normative standard, a standard that carries a distinction between correctness and incorrectness. (In what follows 'normative' will be used to refer to any such standard; the key contrast is with the merely statistically normal.)

The concept of illness, whether bodily or mental, implies deviation from some clearly defined norm. In the case of physical illness, the norm is the structural and functional integrity of the human body. Thus, although the desirability of physical health, as such, is an ethical value, what health is can be stated in anatomical and physiological terms. What is the norm, deviation from which is regarded as mental illness? This 
question cannot be easily answered. But whatever this norm may be, we can be certain of only one thing: namely, that it must be stated in terms of psychological, ethical, and legal concepts... [4]

Szasz used this point as the basis for an argument against mental illness. Nothing can both satisfy this condition and the condition of being medically treatable. Thus one possible route to defend that concept would be to disagree that illness need carry a normative connotation. (A distinct defence is to accept the condition but argue that it does not support the conclusions Szasz draws [5].) Perhaps illness could be defined in merely statistical terms. But as even as biologically minded a psychiatrist as Robert Kendell realised, such an approach cannot work. Reviewing the history of the debate he commented:

By 1960 the 'lesion' concept of disease, and its associated assumptions of a single cause and a qualitative difference between sickness and health had been discredited beyond redemption, but nothing had yet been put in its place. It was clear, though, that its successor would have to be based on a statistical model. [6]

But, as Kendell went on to say, whilst a statistical model may address some of the weaknesses of a single lesion model, statistical abnormality by itself cannot distinguish between 'deviations from the norm which are harmful, like hypertension, those which are neutral, like great height, and those which are positively beneficial, like superior intelligence' [6]. Some further criterion is needed to address the fact that illness is a specific kind of deviation from the norm and Kendell followed the work of the British chest physician, JG Scadding in suggesting that biological disadvantage (including increased mortality and reduced fertility 'whether it should embrace other impairments as well is less obvious' [6]) is the key idea.

More recently there has been an attempt to explain this normative dimension more precisely using the idea of biological or proper function of sub-personal traits (not just advantage or disadvantage to whole individuals). The hope is that whilst illness or disease may carry the irreducible notion of harm, a core notion of disorder can be fitted within a purely descriptive scientific account, drawing on evolutionary theory [7]. The prima facie normative dimension of disorder can be explained through the apparently normative notion of biological function. But functions can be analysed through the plainly descriptive or factual notion of what best explains their continued presence within evolved organisms.

A natural function of a biological mechanism is an effect of the mechanism that explains the existence, maintenance or nature of the mechanism via the same essential process (whatever it is) by which prototypical nonaccidental beneficial effects... explain the mechanism which cause them...

It turns out that the process that explains the prototypical non-accidental benefits is natural selection acting to increase inclusive fitness of the organism. [7]

The aim is thus to capture the prima facie normativity of disorder within a plainly factual scientific account. This non-normative or 'values-out' view is thus one important position in the debate about illness. Disorder, which lies at the heart of illness, can at least be accounted without any irreducible invocation of values.

There are, however, two challenges to this approach. First there is an objection raised originally elsewhere in philosophy that norms are smuggled back into the particular choice of evolutionary explanation $[8,9,10]$. In other words, explanation in terms of biological function is not plainly descriptive. More specifically, for psychiatric disorder, it is unclear that the necessary distinction between natural and merely social functions can be maintained [11].

If one thinks that either of these objections is successful then - in the absence of any other approaches - it seems that to identify some of the behaviour of either a whole person or a subpersonal biological system as expressive of illness is to conceptualise it in irreducibly normative terms. To put this another way, different behavioural dispositions have to be filtered through some sort of normative sieve to yield only those that are expressive of illness or disease. This is a broadly normative or ‘values-in' position. 


\section{The normativity, or not, of recovery}

Just as a central aspect of the debate about illness can be characterised as normative or 'values-in' versus non-normative or 'values-out', the same distinction can be applied to theorising about health. We suggest that a recovery model might plausibly be based on a 'values-in' model of health.

Note, however, that even if one assumes that the concept of illness is essentially normative (statistically unusual behaviour is not sufficient for illness, for example), recovery may not be so. On the 'values-in' picture sketched above, one identifies tracts of behaviour (of people, or of their biological systems) as expressive of illness by filtering all forms of behaviour through an appropriate normative sieve. The filter may use distinct normative terms such as Fulford's failure of ordinary doing or be a primitive and irreducible illness notion such as sufficiently resembling paradigmatic illnesses [12]. Once it has been applied, what remain are normatively selected states or behaviours.

Recovery itself might plausibly be thought of as the return from such states to a state of health. Health itself, however, might be conceptualised in merely statistically normal (rather than normative) terms. If so, whilst the states that individuals have an interest in recovering from are those with particular normative or evaluative properties (whatever precisely those are), recovery itself might be characterised in non-normative non-evaluative terms.

(One might assume that the two debates cannot be independent in the way just suggested. If one adopts a descriptive or values-out view of health, then since illness is, surely, a significant lack of health, illness can inherit a values-out status. In fact, however, this move goes just too quickly. Not all deviations from a statistically normal conception of health would amount to illnesses whilst it is far from clear that attempting to target only illness through talk of a lack of health would remain value-free. Given that our aim is modestly to articulate the space of possibilities we will not presuppose any such link.)

For physical health, a descriptive approach is at least a possible picture although some initial qualifications would be necessary for it to be plausible. Age, for example, makes a difference. What is a healthy physical state for an 80 year old will not be for an 18 year old. (This is not to downplay the burden of aging but to distinguish such burden from pathology or illness.) Further, it may even be statistically normal for most members of particular groups of people (small children, the elderly) to have some illness or other in some or other biological system. If so, and if health were to be defined in normal terms, normality would have to be defined for each such sub-system rather than for the whole person. But given suitable qualification, there is one plausible feature of such an approach: it avoids any idealisation of health. One can be healthy - that is: not ill - without being at the peak of physical condition. The fact that one would prefer to be fitter, stronger or more muscled does not imply that one is not healthy as one is.

An analysis of physical health in statistically normal (rather than normative) terms also helps rationalise a bio-medical approach to recovery. Once the starting point has been identified, a state picked out as an illness, no further mention need be made of normative notions, for example values. Recovery, so construed, would be merely an engineering problem for the human body.

If a non-normative model of physical health helps to rationalise a bio-medical approach, can a contrasting model be articulated for a normative or evaluative model of health? We suggest that one can be based on the following line of thought (although assessing whether or not this line of thought is finally satisfactory is not our concern here). Although it is plausible to define physical health in statistical terms, in the case of mental health, however, the end point might have to be essentially normatively, or more precisely, evaluatively characterised. According to this line of thought, mental health cannot be construed as a statistically average kind of life but rather, in line with the quotation from the Sainsbury Centre policy document, a particular kind of life valued and hoped for by the individual concerned, the kind of life 
connected to their identity.

If this were the case, there would be no hope of defining the endpoint of recovery for mental health in non-normative or non-evaluative terms. A specific endpoint would be correct for, or suited to, each individual. And thus recovery would properly be aimed at a specific and normatively characterised or valued endpoint. This looks to be a way to think of a characteristic recovery model (rather than just a particular approach to recovery) because it turns on a theoretical view of the nature of health towards which recovery aims. It merits the name 'model'.

Is this the only way of approaching the nature of mental health? Is a recovery model the only plausible approach to mental health? We do not think so. To defend, rather than merely rationalise, a recovery model for mental health so construed would require dismissing a variant of the statistically normal approach. Whilst characterising a statistically normal kind of life seems misguided, the capacities that enable one to live such a life may be more appropriate for that treatment. So, in the service of a valued and hoped for life, mental health might be defined in terms of statistically normal mental capacities and abilities. Our aim here, however, is not to argue for a recovery model but to explore its place in the range of options.

To summarise this section, contrasting approaches to health help to justify two contrasting approaches to recovery:

Recovery ${ }_{1}$ : a return to normality (albeit from a position picked out by a normative sieve). Recovery $y_{2}$ : a move (from a position picked out by a normative sieve) to a normatively characterised endpoint, for example, a conception of a valued form of life.

Recovery 2 suggests that whether someone has recovered or not depends not on the plainly descriptive matter of whether they have returned to a statistically normal state but rather on reaching a normatively or evaluatively characterised state that constitutes wellbeing. We suggest that this could form the basis of a recovery model of mental health, a model which would stand in genuine contrast to a bio-medical model based instead on recovery

Although we have merely sketched the conceptual space for a recovery model rather than arguing for it we will end by drawing attention to two potential objections. By briefly considering these, we can offer one final potentially helpful distinction and indicate something of the work that would remain for justifying a recovery model.

\section{The right values for recovery?}

The key assumption in our rationalisation of a recovery model for mental health is that the endpoint of recovery has to be characterised in normative or evaluative terms. On this view, there is something appropriate or correct rather than merely usual about the endpoint. But, perhaps because of the rise of autonomy as the key medical ethical value, there is a standing temptation to construe this normative dimension in a particular way. That is, in accord with the desires and choices of the individual concerned. (And put like that, it is tempting to wonder who else's desires and choices should be preferred.) Nevertheless, if the norms in play primarily reflect individual desires and choices then this threatens to open up a gap between recovery and health and also puts the idea of social inclusion at the level of communities under pressure.

We do not wish to underplay the difficulties here. Any recovery model based on our suggestion would have to identify why the normatively or evaluatively charged endpoint was constitutive of mental health rather than some other valued aim or end (of which health might be merely an aspect). Establishing that mental health is an essentially evaluative notion is not sufficient for saying which values are specifically relevant for mental health and thus which values are excluded from that analysis. Nevertheless, we suspect that there are more and less promising approaches based on contrasting views of wellbeing.

Consider two contrasting views of wellbeing: hedonic and eudaimonic. On the hedonic view: wellbeing is essentially a matter of maximising utility; and, on the assumption that what 
people actually desire remains our only reliable guide to what is desirable [13], in practice a matter of ensuring that individuals' key desires are satisfied as far as possible. The normativity of recovery based on this approach is exhausted by the combination of utility maximisation, and by issues of rationing of scarce resources or balancing conflicting desires. (There may have to be some further normative standards operative in any plausible version of this idea concerning, eg., the coherence of one's desires and the continence of one's judgements. Nevertheless, such constraints remain internal and individualistic.)

On a eudaimonic view, wellbeing consists in living the kind of live that exemplifies the finest distinctively human capacities - the characteristic virtues of human beings. In Aristotle's phrase, it is 'activity in accordance with virtue'. It thus builds in the idea that some values are more valuable than others - beyond matters of individual coherence - and not merely more (that is, statistically) desired. The approach retains a key role to individual choice (since it recognizes the capacity for sound deliberation as among the most important human capacities), and for pleasure (since pleasure will typically accompany the exercise of those capacities) . But individuals' desires and their satisfaction are no longer regarded as the measure of wellbeing. By keeping the key connection between eudaimonia and wellbeing in focus, an approach to recovery based on this conception of wellbeing could better restrict the kind of values that characterise its aim. There remains a gap between wellbeing and mental health but a eudaimonic approach looks to be a more promising first move.

Thus, in addition to the normative standards implicit in the hedonic view, a eudaimonic view introduces two further degrees for normative assessment. First, the values that characterise the endpoint of recovery are not just any (coherent) desires and choices but values connected to human flourishing. This looks to be a more promising route to maintain the pre-theoretic notion that recovery is connected to health, whatever the precise relation between mental health and wellbeing might be. Second, values can be better or worse and can be subject to rational criticism and scrutiny. Thus, for example, if human flourishing really does depend on social inclusion then that fact places principled limits on the value of individual autonomy and thus principled limits on the nature of recovery. Not just any preferred endpoint constitutes the proper aim of recovery, so construed.

Having sketched the conceptual space for a normatively charged conception of recovery based on a eudaimonic view, we will finish with three clarificatory comments.

First, Aristotle himself held substantial views about the nature of human flourishing. For example, he regarded 'magnificence' ('megaloprepeia') as an important virtue. While we might well question many of the ingredients of Aristotle's view, a broadly eudaimonic view of recovery need not be tied to any such substantive view of flourishing. What flourishing is would need to be investigated and subjected to ongoing critical scrutiny.

Second, especially in the light of the flight from medical paternalism to patient or service user autonomy, the idea that some values are more valuable than others might smack of authoritarianism and thus serve to rule out such an approach from the start. But it need not. Just as the empirical world serves a normative standard for what empirical beliefs we should hold without that fact implying that science has to be authoritarian, so a conception of real and objective values need not lead to authoritarianism either. Rather, it imposes a standing obligation for critical reflection on the values we do hold.

Third, the eudaimonic view of recovery does not preclude a role for hedonic values in mental health care. Sincerely held, harmless hedonic values may indeed play a role in a broader values based practice. The desires and choices of service users, who indirectly pay for the services, should indeed be taken into account in commissioning, for example. And thus models for managing competition for limited resources and other values-based conflicts will be needed. But it is surely a point in the favour of the eudaimonic view that such values would not determine what we ordinarily understand by 'recovery' and its direct connection to health. 


\section{Conclusions}

We have sketched a recovery model for mental health distinct from a bio-medical model according to which recovery is a characterised in non-normative and value-free terms. On the alternative view sketched above, the goal of recovery has to be determined through the conception of a life to be valued and hoped for by the subject concerned. Such a conception is normative or value-laden in so far as it fits, or is appropriate to, or correct for, the individual's self-identity. By connecting recovery to a value-laden conception of health we have articulated the conceptual space for a recovery model which stands in genuine contrast to a bio-medical model.

There is a danger, however, that such a view would sever the connection between recovery and health and undermine the often connected goal of social inclusion. For those reasons we have suggested if a recovery model is adopted based on a connection to a 'values-in' model of health, the values in play are more promisingly thought of as eudaimonic than hedomic.

It is, of course, one thing to sketch the conceptual space for a recovery model of mental health. It is another to argue convincingly for it.

\section{References}

1. Davidson L, and Roe D, Recovery from recovery in serious mental illness: one strategy for lessening confusion plaguing recovery. Journal of Mental Health 2007;16:459-470

2. Shepherd G, Boardman J, \& Slade M, Making Recovery a Reality London: Sainsbury Centre for Mental Health 2008:0

3. Davidson L, Strauss JS, Beyond the biopsychosocial model: integrating disorder, health, and recovery. Psychiatry 1995;58:44-55

4. Szasz T, The Myth of Mental Illness, London: Paladin 1972:15

5. Thornton T, Essential Philosophy of Psychiatry Oxford: Oxford University Press 2007

6. Kendell RE, The concept of disease and its implications for psychiatry. British Journal of Psychiatry 1975;127:305-315

7. Wakefield JC, Mental disorder as a black box essentialist concept. Journal of Abnormal Psychology 1999;108:465-472

8. Peacocke, C. (1992) A study of concepts, Cambridge, Mass.: MIT Press

9. Thornton T, Wittgenstein on Language and Thought, Edinburgh: Edinburgh University Press 1998: 30-68

10. Thornton T, Mental Illness and Reductionism: Can Functions be Naturalized?. Philosophy, Psychiatry and Psychology 2000;7:67-76

11. Bolton D, What is Mental Disorder, Oxford: Oxford University Press 2008:124-5

12. Fulford KWM, Moral Theory and Medical Practice, Cambridge: Cambridge University Press 1989:131

13. Mill JS, Utilitarianism, in Warnock M, (ed.) Utilitarianism, London: Fontana 1962 